\title{
ITIL v3 and Van Grembergen Framework for System Transition Process
}

\author{
Desi Wulandari ${ }^{1}$ and Joko Lianto Buliali ${ }^{2}$
}

\begin{abstract}
Recently, PT XYZ replaced their old ERP system into the Microsoft Dynamics AX 365. PT XYZ has twenty branch offices. The system transition process uses direct conversion and pilot conversion models. This study reports on how ITIL 13 and Van Grembergen Framework can work together in developing guidelines for system transition processes. This study was conducted by mapping the organizational structure, processes, and relational mechanisms in accordance with the Van Grembergen framework. The results obtained from this mapping will be used as material for consideration for the preparation of governance using the ITIL $v 3$ framework. This research will only use the Service Transition domain on ITIL. The questionnaire was taken in part from the template issued by UCISA. As a result of the study, we present that ITIL v3 and Van Grembergen are able to be used to rebuild structures, processes, and relational mechanisms after the system transition process is done. And also to improve how to do the next transition process in another branch offices. Organizations must adapt and adapt to changes that means, Organizations cannot only carry out practices that have been done and hoped for get success like what happened in the past, because the practices in the past that have been done may not be valid now because the environment has changed. Therefore, in this case if organizations wants to achieve and gain a competitive advantage, it must focus and make changes to the goal strategic, having a far-sighted future.
\end{abstract}

Keywords-Information Technology Governance, ITIL v3, Van Grembergen, System Transition Process.

\section{INTRODUCTION}

Nowadays, Information Technology plays an important role in organizations, not only as support equipment. In recent years the concept of IT governance represents a well-discussed set of concepts for ensuring the 'optimal' utilization of IT for the benefit of a business [1]-[4]. Corporate Governance is a guideline designed to direct corporate management based on the principles of transparency, accountability, responsibility, independence, fairness, and equality. Implementation of Good Corporate Governance (GCG) has the Company's mission to create competitiveness, create added value, and implement good governance. System transitions are part of organizational reinforcement strategies and important decisions because many failed ERP implementations by companies in

\footnotetext{
${ }^{1}$ Desi Wulandari is with Departement of Management Technology, Institut Teknologi Sepuluh Nopember, Indonesia. Email: Desiwulan1992@gmail.com.

${ }^{2}$ Joko Lianto Buliali, Department of Informatics, Institut Teknologi Sepuluh Nopember, Indonesia. Email: joko@its-sby.edu.com.
}

Indonesia are caused by over budget, over time in project execution, lack of system performance and unexpected benefits. This system transition causes a lack of focus on daily operations tasks to maximize source tasks in IT operations and maintain projects. This is due to the undefined tasks and clear functions of all IT. The cause is the lack of communication and the relationship between IT and business. This causes the IT staff to not be responsive to business needs. This can also cause businesses cannot clearly understand the advice of IT staff. The system transition make old information technology governance needs to require an update to stay the same as the company's main goal. This research using two frameworks of IT Governance; The IT Infrastructure Library (ITIL) and structures, processes and relational mechanisms from Van grembergen. This research using Van grembergen model to get the map about structures, processes, and relational mechanisms in this organization. The result from this mapping will be used as a consideration to make a proposal Roles, structures, and relational mechanisms improvement in PT XYZ. This research focuses on Service Transition Process. That's why we choose ITIL. ITIL has Change Management inside the Service Transition process. The assessment will be using a questionnaire from UCISA. An assessment will be conducted to find out how well the system transition has been done.

\section{LiterATURE REVIEW}

\section{A. IT Governance}

IT governance is a fundamental part of corporate governance and contains of leaders, organizational structures and processes that guarantee the sustainability of IT, and how IT can be developed and help expand organizational strategies and objectives. IT governance is how to organize the use of IT in order to produce maximum output in the organization, help the decisionmaking process and help the problem-solving process. The principles of IT governance must be carried out in a structured and integrated manner as well as implemented in a company.

\section{B. Transition System}

The purpose of Service Transition processes in Figure 1 is:

a. Plan and manage service changes efficiently and effectively. 
The $1^{\text {st }}$ International Conference on Business and Management of Technology (IConBMT)

August 3rd 2019, Institut Teknologi Sepuluh Nopember, Surabaya, Indonesia

b. Manage risks related to new, modified, or retired IT services.

c. Successfully releasing and implementing IT services to the actual support environment.

d. Manage expectancy for performance and use of new services or modified services.

e. Ensuring service changes produce business value as expected.

f. Providing quality knowledge and information related to service and service assets.
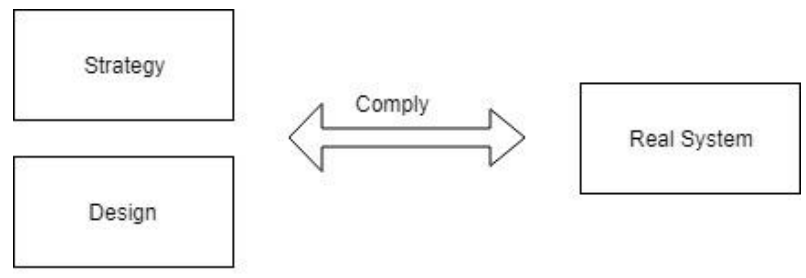

New / Modified / Retired System

Figure 1. Purpose of Service Transition Processes

The Transition process system uses the Direct conversion model and according to location uses the Pilot Model. Based on the results of observations in the field, the results of interviews were also from the results of business document analysis, chosen by one company goal that is currently needed by PT XYZ, how to make a system transition in another company branch with minimal risk as possible as it can. The impact of it is that business processes also change. If the structure and process changes, it can be ascertained that the relational mechanisms also changes. This is because the structure, processes and relational mechanisms are mutually sustainable.

\section{Van Grembergen Model}

The application of IT governance requires a combination of structures, processes and relationship mechanisms for both (structure and process) [3]. Hierarchy can be illustrated the relationship between structure, process and relational mechanisms in Figure 2.

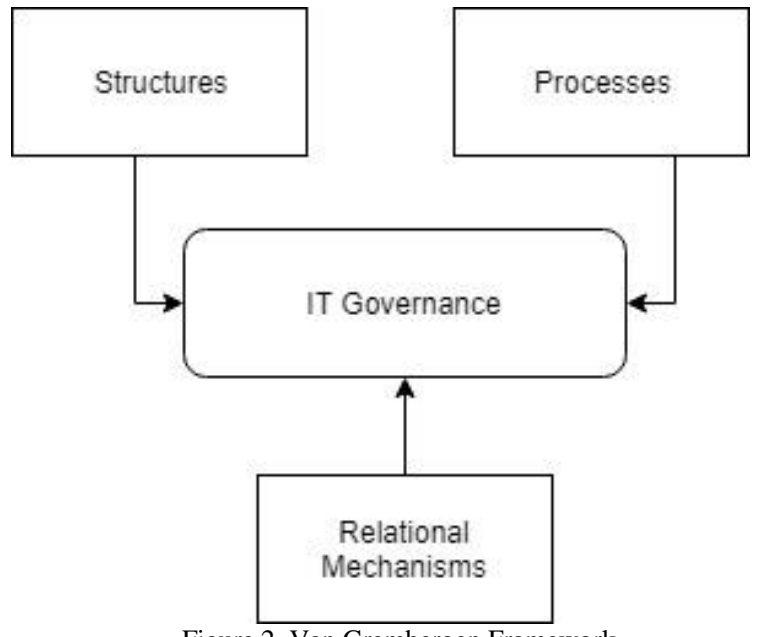

Figure 2. Van Grembergen Framework
The structure in this case means the basic things that must be built or as the foundation for IT governance to work. The structure includes the IT organizational structure, the division of roles and responsibilities. IT organizational structure includes how IT functions are organized, and where decision-making authorities are placed in the organization. Division of roles and responsibilities requires clear and unambiguous definitions of roles and responsibilities for board and executive management, as well as business performance and compliance reporting systems. The board and management carry out regulatory tasks through the IT Strategic Committee and ensure that IT is a regular agenda in their activities. Processes means tasks carried out in order to implement IT governance, such as ITIL framework. That's why we use ITIL framework in this research. Process is the whole process associated with strategic decision making. In addition to structure and process, the third thing is the relational mechanism is an important thing that takes part in the implementation of IT governance based on Van Grembergen model. This is because even though the structures and processes that have been running well, it cannot be used as collateral for the achievement of IT governance, they must be supported by two-way communication between IT and other business units. To achieve effective IT governance requires two-way communication, good participation and collaborative relationships between business people and IT people. It is very important to facilitate sharing, knowledge management, continuous education and cross training. In addition, the relational mechanisms can also be achieved through active participation and collaboration between stakeholders, rewards and incentives, business/IT colocation, cross functional business/IT training and rotation.

\section{ITIL v3 Framework}

IT Infrastructure Library (ITIL) is an IT governance model that contains of a set of services for IT Service Management (ITSM) that focus on matching IT services with business needs.

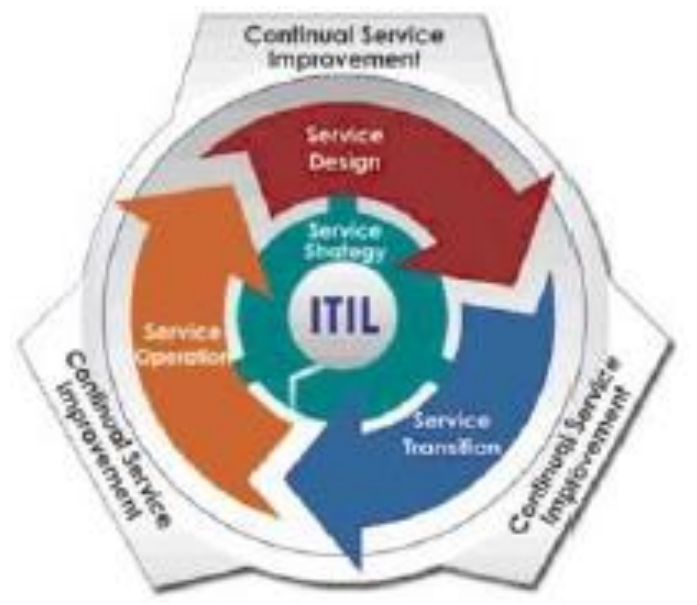

Figure 3. ITIL Framework 
Service Transition provides guidance to IT organizations to be able to develop and the ability to change the results of new IT service designs and IT services that have been changed to be operational specifications. Service Transition is between Service Design and Service Operation, it means Service Transition is a step that contains processes to develop (build, test and implement) a service design produced by Servcie Design into an IT or modified system or service, to then submit it to the process -processes in Service Operations to be used and operated in daily IT service operations. The aim of Service Transition is to ensure new, modified, or stopped services (retired services) truly meet business expectations as documented in Service Strategy and Service Design in Figure 3.

\section{METHODOLOGY}

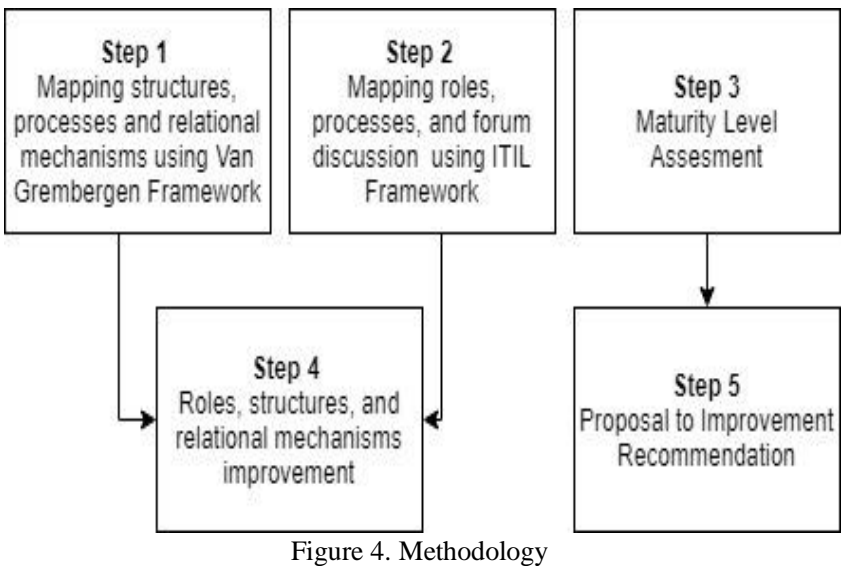

\section{A. Mapping Structures, Processes and Relational Mechanisms}

To analyze the structure is to map the highest IT leaders in each of the highest divisions, then analyze and determine the highest level of IT leadership in the organizational structure. This is to find out the vertical depth of the highest leadership level of IT towards the highest leadership in the organization. By knowing the level of IT leadership can be analyzed how the position of IT in the organization. The next structure mapping is a mapping for the implementation of committees and Project Management Office (PMO) in organization. The committees are the IT Steering Committee, the IT Project Committee Committee, and the Risk Committee. Then mapping the IT governance process. Mapping describes the roles involved in the IT Project Lifecycle in an organization. The roles involved in the process of implementing IT projects are those who make proposals, approvals, priorities, approval of priorities, budgets, development, evaluation, maintenance and monitoring. Then mapping the relational mechanism that occurs in the organization. Mapping explains the relation mechanism, the functions and roles involved in the mechanism.

\section{B. Mapping Roles, Processes, and Forum Discussion using ITIL Framework}

We need modification and clarifying roles and responsibilities in the system's transition process. The description of specific roles and responsibilities for each user who is directly involved is important to do, this aims to ensure the system transition process can run well. There are seven roles or roles in the division of recommended roles according to the ITIL v3 framework, they are Change Requestor, Change Implementers, Change Owners, Service Owners, Change Managers, Testing Teams, and Evaluators. After the recommendation of the role that is currently available at PT XYZ and in accordance with the ITIL v3 framework, the next discussion forum will be conducted in accordance with the current conditions. After Roles and Forums have been completed, the next step is to combine roles and forums at the process step. The processes step is a step that requires roles and forums as an activity happened in the system transition process.

\section{Maturity Level Self-Assesment}

There are two ways of the Self Assessment Service model; full self-assessment and high level self-assessment. Full Self-assessment, provides access to a full range of questions for each process and function. This assessment contains of more than 2600 additional questions and it is designed to provide appropriate maturity values with round decimal values. High level self assessment, offering assessment with limited questions only up to 50 questions per process and starting from 0.5 from the decimal place of achievement level. This research using High Level SelfAssesment. At high-level self-assessment, the assessment focuses on 9 assessment focus areas that contain questions that indicate the achievement of each focus area: Pre requisites, Management Intent, Process Capability, Internal Integration, Products, Quality Control, Management Information, External Integration, User Interface.

\section{Roles, Structures, and Relational Mechanisms Improvement}

After creating a list of roles and responsibilities for each role, then the results of the mapping from the Van grembergen model that have been made previously will be combined with the results of the roles and responsibilities of using the ITIL framework. Based on the priority given, the design of improvement recommendations will be mapped by mapping the structure, process and relational mechanisms in accordance with the Van Grembergen framework that we have done before. After making recommendations for the structure by combining the results of the mapping with Van Grembergen and ITIL, after that a recommendation was made for the mechanism of the relationship with the results of the mapping using the Van Grembergen and ITIL framework. After that, recommendations were made for the process of the results of the Van grembergen and ITIL framework mapping that 
had been done previously. At this step, the merging of the results of the mapping of the processes at PT XYZ using the Van Grembergen model with the results of the mapping of the processes at PT XYZ using the ITIL framework.

\section{E. Proposal to Improvement Recommendation}

By referring to the expectations (ideal conditions) that the key user team wants to achieve, it is necessary to develop steps or actions that can be taken to improve the current transition process system conditions, in the form of recommendations for improvements referring to the directions provided by the framework ITIL, and has been adapted to the environmental conditions that exist in PT $\mathrm{XYZ}$, both in terms of operational and business aspects. Proposal of recommendations for these improvements can be done by mapping existing conditions based on mandatory (red label) structural elements and nonmandatory structural elements and structural elements that need to be refined (yellow label). It aims to produce structured, directed and targeted recommendations for improvement to achieve maximum results.

\section{RESUlt AND DisCUSSION}

\section{A. Collect Data}

In this study data collection was conducted using Focus Group Discussion (FGD) methods, questionnaires, and field studies. The purpose of the FGD was to find information regarding the condition of information technology governance at PT XYZ and the conditions that company's wants. The FGD method was chosen because this method provides independency for participants to deliver their ideas, opinions and input as long as they are within the framework of the FGD objectives. Data obtained from the FGD method is more detailed data compared to using the questionnaire method only. Because the questionnaire method only gives an assessment of predetermined attributes. In this FGD, 6 participants were selected based on the common knowledge of the company's business processes, how the old system went, how the new system was being implemented at this time. The FGD method was done by giving a general description of the topics discussed, the purpose of the discussion and the mechanism carried out during the FGD. The standard questions in the questionnaire were used as measurement tools so that discussions with FGDs became more targeted. The questionnaire was carried out to be able to assess the current level of information technology capabilities. Questionnaire making follows the questionnaire template from UCISA and the Office of Governance Commerce (OGC) compiled by Stephen Kent. Participants are all roles directly related to the system's transition process. Respondents are presented in Table 1 below.
TABLE 1.

RESPONDENTS

\begin{tabular}{clc}
\hline \hline No & \multicolumn{1}{c}{ Respondents } & Quantity \\
\hline 1. & Chief Finance Controller & 1 \\
2. & Branch Manager & 1 \\
3. & Manager Quality Control & 1 \\
4. & Manager Internal Audit & 1 \\
5. & Supervisor TI & 1 \\
6. & Manager RnD & 1 \\
& Total & 6 \\
\hline \hline
\end{tabular}

\section{B. Data Processing}

Based on the results of the FGD that was held on May 24, 2019 in the VIP meeting room of the head office of PT $\mathrm{XYZ}$, it was found that at this time the system transition process carried out by the implementation team and consultants. They had a level of maturity at level 3 "Products", such as which is in Appendix 1. Where at that level it can be stated that the organization has been able to ensure that the output obtained from the Service Transition process is being implemented, the output is a new system that can operate and be used by users for operational and management activities. But indeed the results are not optimal because according to the FGD results the time needed to achieve these results is quite long when compared to the old system. Each level of assessment contains of a set of weighted structural elements, there are structural elements that have a greater weight than the others and are marked with the letter "M". Each level also has a minimum value that must be passed before being able to move to the next level, this aims to see areas that still need to be improved first in improve a better Service Transition process.

TABLE 2.

COMPARISON BETWEEN QUESTIONNAIRE RESULTS AND CONDITIONS OF EXPECTATION

\begin{tabular}{lcc}
\hline \hline \multicolumn{1}{c}{ Items } & Score & Maximum Attainable Score \\
\hline Pre-Requisites & 3 & 4 \\
Management Intent & 3 & 4 \\
Process Capability & 15 & 17 \\
Internal Integration & 8 & 9 \\
Products & 2 & 6 \\
\multicolumn{1}{c}{ Total } & 31 & 40 \\
\hline \hline
\end{tabular}

In this questionnaire the results for Pre-requisites items only get 3 points out of a total of 4 expected points. The value of 3 points for Pre-requisites is enough to exceed the "Pass" limit. For Management Intent items, the current conditions at PT XYZ get a value of 3 points out of a total of 4 points Maximum Attainable Score. This value is enough to be able to continue the assessment to the next item. Then for Process Capability, get a value of 15 points from the total value of 17 points expected, then the result is "Pass". In Internal Integration get 8 points for a total of 9 
maximum attainable score points, so that we can continue the assessment at the Products step. For products, PT XYZ only gets 2 points from the expected 6 total points. And for one of the mandatarory points there is a value of "N", then the assessment must be stopped on the Products items only.
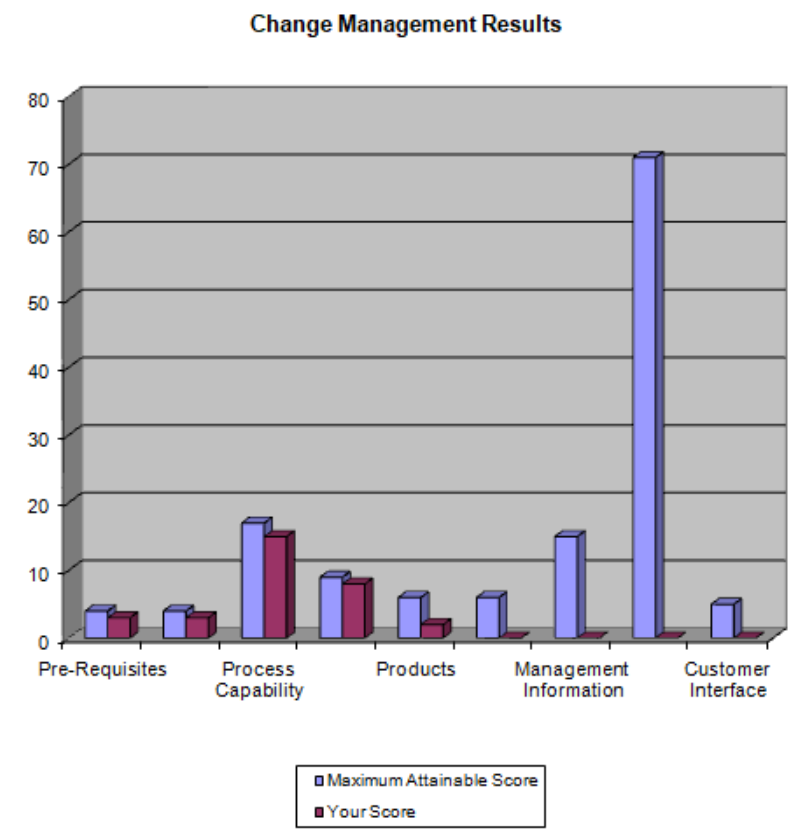

Figure 5. Result of Questionnaire

\section{Data Analysis}

By referring to the results of the self-assessment that has been done on the system transition process, the mapping does not cover all levels of maturity that can be measured using ITIL Change Management Self-Assessment (Level 5). However, this mapping is only carried out up to level 3 - "Product", which is the last level that cannot be passed by the system transition process in this self-assessment as well. Based on the results of the mapping between the system transition process conditions that have been carried out in the 2 current branches of the company and the expectations or local conditions to be achieved along with the label. Giving labels "red", "yellow", and "green" on each point indicates the priority of each structural element found in the ITIL Self-Assessment for the IT Change Management process. There are some things that have met the standard requirements of a good IT Change Management according to the ITIL framework, but there are still many forms of improvements that must still be applied by the organization to achieve the expected results and in accordance with the company's business needs.

\section{1) Red Label}

Red label on a structural element describing the current condition of IT Change Management does not meet the requirements requested, through questions that are Mandatory (M) and have a greater weight than the other questions, so that they are needed to be prioritized.

\section{2) Yellow Label}

The yellow labeling of a structural element describing the current IT Change Management condition does not meet the requirements requested, through non-mandatory questions, as well as IT Change Management conditions that have met the requirements requested but from the operational side want improvement for these conditions.

\section{3) Green Label}

Giving a green label on a structural element illustrates the current condition of IT Change Management that has fulfilled the requirements requested, through the structural elements in the ITIL Self-Assessment for Change Management.

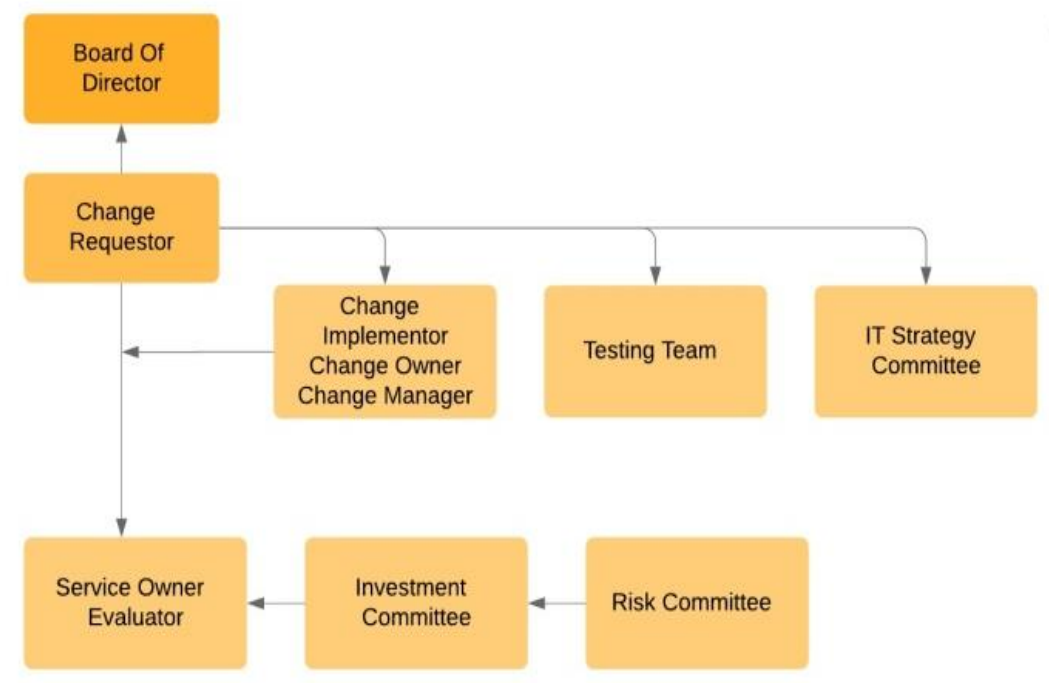

Corporate Governance

Figure 6 New Structure of PT XYZ

Operational IT Governance
Strategic IT Governance 


\section{Structures, Processes and Relational Mechanisms}

\section{1) Structures}

The structures that is in the mapping of the Van Grembergen model has been done. There are three major parts, they are Corporate Governance, Strategic IT Governance, and Operational IT Governance. The Board of Directors is included in the Corporate Governance section. While in the Strategic IT Governance there is an IT Steering Committee. In the IT Steering Committee there is the IT Project Steering Committee, Audit Committee, and IT Strategy Committee. In the Operational IT Governance section there is a PMO, Investment Committee and Risk Committee. While in Figure 6 illustrated how the condition of the structure after being combined with the ITIL framework. In the IT Steering Committee section there is Change Requestor. Because the Change Requestor is responsible for creating and submitting an RFC (Request for Change), change requestor can also act as a Change Implementer for its role. For the IT Project Steering Committee there are Change Implementers, Change Owners, Change Managers because the three of them are fully responsible for overseeing the system transition process. Together with the Testing Team and the IT Strategy Committee including the Strategic IT Governance section. This section is responsible for implementing the change plan and reporting on the results of the implementation, ensuring the quality and effectiveness of the Change Requestor and Change Implementers, ensuring that the proposed RFCs are in line with the existing system transition process standards, and ensuring the quality of changes, by doing UAT and Sanity test. While for the last part, they are Operational IT Governance, there are Service Owners, Evaluators, Investment Committee and Risk
Committee. This section is responsible for informing and approving changes. The party responsible or evaluating the quality of a change that has been implemented, both in terms of business operations and customer satisfaction, ensures that the vision and mission of the system transition process are fulfilled and oversees the design, development, and implementation of IT governance and policies processes showed in Table 3.

\section{2) Relational Mechanisms}

After making recommendations for the structure by combining the results of the mapping with Van Grembergen model and ITIL framework, recommendations were then made for the relational mechanisms with the results of the mapping using the Van Grembergen and ITIL framework. Change Control Board, Change Advisory Board and Emergency $\mathrm{CAB}$ are included in the Project Meeting because all three activities must be done when the project is running. The topics raised in the three activities are assessing the completeness, validity and analysis of the impacts and risks of each change, helping the role of CCB in assessing completeness, validity and analyzing the impact and risks of significant changes, and analyzing the impacts and risks of changes aimed at improving errors in IT services that can have a negative impact on business to very high levels. This forum contains of Team Incidents (if related to incidents), change manager and head of each IT unit. For more details, see in Figure 7.

TABLE 3

ROLES AND RESPONSIBILITY

\begin{tabular}{llcll}
\hline \hline Requestor & Approval & Prioritized & Priority Approval & Budgeting \\
\hline User & BOD & BOD & BOD Meeting & BOD \\
& & Meeting & & Meeting \\
\hline \hline
\end{tabular}

TABLE 4.

PMO UNIT IN PT. XYZ

\begin{tabular}{|c|c|c|c|c|c|c|c|}
\hline $\begin{array}{l}\text { IT Steering } \\
\text { Committee }\end{array}$ & $\begin{array}{c}\text { IT Project Steering } \\
\text { Committee }\end{array}$ & $\begin{array}{l}\text { IT Strategy } \\
\text { Committee }\end{array}$ & $\begin{array}{c}\text { Audit } \\
\text { Committee }\end{array}$ & $\begin{array}{l}\text { Investment } \\
\text { Committee }\end{array}$ & $\begin{array}{c}\text { Risk } \\
\text { Committee }\end{array}$ & $\begin{array}{c}\text { Project Management } \\
\text { Office }\end{array}$ & Total \\
\hline- & $\sqrt{ }$ & - & - & - & - & - & 1 \\
\hline
\end{tabular}

TABLE 4

ROLES AND RESPONSIBILTY

\begin{tabular}{cccc}
\hline \hline Development & Evaluate & Maintenance & Monitoring \\
\hline IT Group, Vendor, key user & Corporate Chief Financial Controller & IT Group, Vendor, key user & IT Group, Vendor, key user \\
\hline \hline
\end{tabular}

\section{3) Processes}

There are 4 phases, namely Proposal, Assessment, Development and Evaluation. In the proposed phase, there is an RFC. This is the first step of the system transition process. If there is a change that occurs, the first thing done by Change Requestor is to create an RFC. Then go to Phase 2, namely the assessment phase. In it there is agreement, how is the budget, prioritization, and authorization of priority. All of these assessments were carried out by the Risk Committee, Investment Committee,
Service Owner, Evaluator. These activities were carried out at the BOD Meeting and Project Meeting discussion forums. In phase 3, that is entering the development step, in which there is build, test, scheduling and implementation. In this phase the responsible role is Change Implementor, Change Owner, Change Manager, Testing Team and IT Strategy Committee. This activity will be conducted at the Project Meeting discussion forum, IT Group Monthly Meeting, Join Discussion. As for the evaluation phase, there are reviews, maintenance, and monitoring how the 
new system is running. The roles responsible for this phase are Change Implementor, Change Owner, Change Manager, Testing Team and Evaluator. As for the relational mechanisms for this last phase are Project Meetings, IT Group Monthly Meetings, Join Discussions.

TABLE 5 .

RELATIONAL MECHANISMS

\begin{tabular}{ll}
\hline \hline \multicolumn{1}{c}{ Relationship } & \multicolumn{1}{c}{ Roles } \\
\hline IT Group monthly meeting & IT Group \\
Biweekly meeting & IT Group, User, dan Manajemen Group \\
Project meeting & IT Group dan Key user \\
Join Discussion & Vendor, IT Group dan Key User \\
BOD Meeting & BOD Group \\
\hline \hline
\end{tabular}

\section{4) Making Recommendations}

By referring to the expectations (ideal conditions) that the key user team wants to achieve, it is important to develop steps or actions that can be taken to improve the current transition process system conditions, in the form of recommendations for improvements referring to the directions provided by the framework ITIL, and has been adapted to the environmental conditions that exist in PT $\mathrm{XYZ}$, both in terms of operational and business aspects. Proposal of recommendations for these improvements can be done by mapping existing conditions based on mandatory (red label) structural elements and nonmandatory structural elements and structural elements that need to be refined (yellow label). Referring to the table 4 above and the limitations of the problems that have been previously set, it can be concluded that the recommendations for improvements that need to be made are:

a) Design an evaluation mechanism routinely as part of improving the System Transition process

b) Add a multilevel validation process as part of improving the system transition process c) Designing a mechanism for handling escalation of the approval process as part of improving the System Transition process

d) Design the priority matrix as a part of improving the System Transition process

e) Increase PIR by including the information needed as part of improving the system transition process

f) Establish an ITSM Executive Committee as part of making and modifying and clarifying the roles and responsibilities of each stakeholder involved in the system transition process

g) Designing mechanisms for handling violations of system transition (unauthorized changes) as part of improving the system transition process

h) Make a mechanism for making failure reports as part of improving the system transition process

i) Add information components about business goals as part of improving the system transition process

j) Designing an emergency handling mechanism because urgent business is part of improving the system transition process

k) Designing RFC documentation standards as part of improving the system transition process.

TABLE 6.

STRUCTURE RECOMMENDATION

\begin{tabular}{clc}
\hline \hline No & \multicolumn{1}{c}{ Role } & Source \\
\hline 1 & Change Requestor & User \\
2 & Change Implementer & IT Group ; Vendor \\
3 & Change Owner & BOD Group \\
4 & Service Owner & BOD Group \\
5 & Change Manager & Key User \\
6 & Testing team & Key User ; Quality Control ; User \\
7 & Evaluator & CFC \\
\hline \hline
\end{tabular}

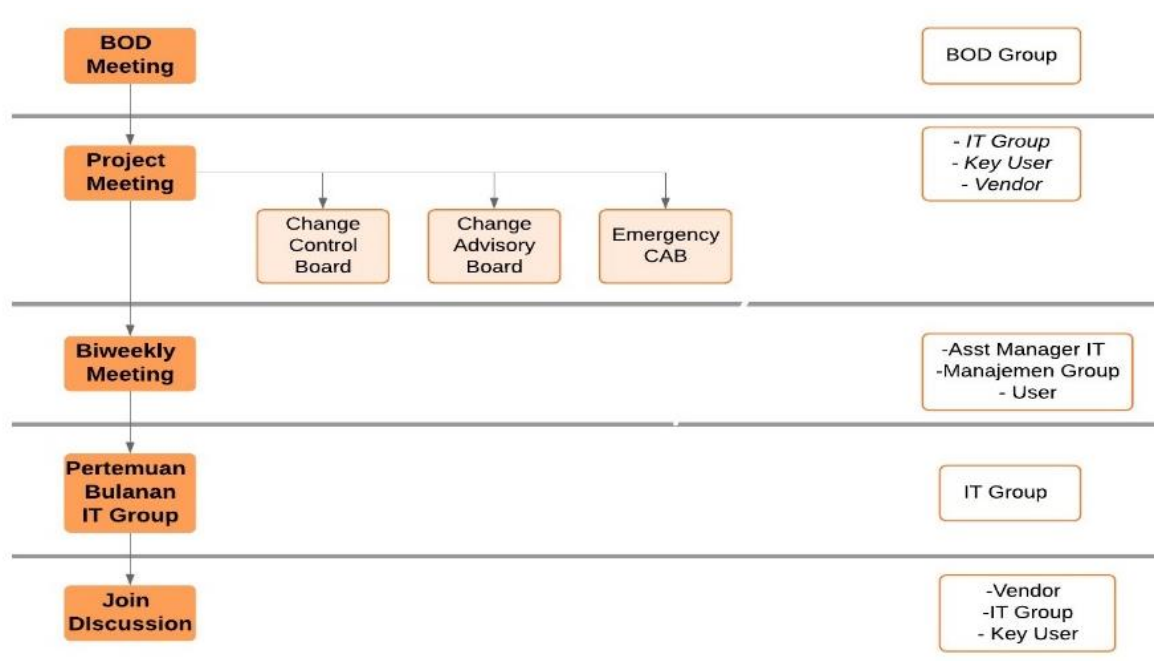

Figure 7. New Relational Mechanism of PT XYZ 
The $1^{\text {st }}$ International Conference on Business and Management of Technology (IConBMT)

August 3rd 2019, Institut Teknologi Sepuluh Nopember, Surabaya, Indonesia

TABLE 7.

NEW PROCESSES PF PT XYZ

\begin{tabular}{|c|c|c|c|}
\hline Phase & Processes & Structures & Relational Mechanisms \\
\hline 1 & $\begin{array}{l}\text { Request } \\
\text { - Make RFC }\end{array}$ & Change Requestor & BOD Meeting \\
\hline 2 & $\begin{array}{ll}\text { Assesment } \\
\text { - } & \text { Approval } \\
- & \text { Budgeting } \\
- & \text { Prioritized } \\
\text { - } & \text { Priority Approval }\end{array}$ & $\begin{array}{ll}\text { - } & \text { Risk Committee } \\
\text { - } & \text { Investment Committee } \\
\text { - } & \text { Service Owner } \\
\text { - } & \text { Evaluator }\end{array}$ & $\begin{array}{ll}- & \text { BOD Meeting } \\
- & \text { Project Meeting }\end{array}$ \\
\hline 3 & $\begin{array}{ll}\text { Development } \\
\text { - } & \text { Build } \\
\text { - } & \text { Test } \\
\text { - } & \text { Scheduling } \\
\text { - } & \text { Implementation }\end{array}$ & $\begin{array}{ll}\text { - } & \text { Change Implementor } \\
\text { - } & \text { Change Owner } \\
\text { - } & \text { Change Manager } \\
\text { - } & \text { Testing Team } \\
\text { - } & \text { IT Strategy Committee }\end{array}$ & $\begin{array}{ll}\text { - } & \text { Project Meeting } \\
\text { - } & \text { IT Group Meeting } \\
\text { - } & \text { Join Discussion }\end{array}$ \\
\hline 4 & $\begin{array}{ll}\text { Evaluating } \\
\text { - } & \text { Review } \\
\text { - } & \text { Maintenance } \\
\text { - } & \text { Monitoring }\end{array}$ & $\begin{array}{ll}\text { - } & \text { Change Implementor } \\
\text { - } & \text { Change Owner } \\
\text { - } & \text { Change Manager } \\
\text { - } & \text { Testing Team } \\
\text { - } & \text { Evaluator }\end{array}$ & $\begin{array}{ll}\text { - } & \text { Project Meeting } \\
\text { - } & \text { IT Group monthly meeting } \\
\text { - } & \text { Join Discussion }\end{array}$ \\
\hline
\end{tabular}

\section{CONCLUSION}

After conducting the FGD and justification using the UCISA questionnaire based on the ITIL version 3 framework, the results show that the current system transition process at the branch of the company has a level of maturity at level 3 - Products. This means at this level it can be stated that PT XYZ has been able to ensure that the outputs obtained from the system transition process are being carried out, where the output can be in the form of monthly reports or weekly reports in order to meet operational and management needs.

The results of the mapping of the Van Grembergen framework and the results of the ITIL version 3 mapping if combined, will complement each other. According to Van Grembergen's model, IT governance contains of the structure, process and relational mechanisms between the two. Here after mapping, the structure and relational mechanisms at PT XYZ were repaired by combining the results of the mapping from van grembergen and ITIL. The structure relates to the roles and responsibilities of HR during the system transition process, while the relationship mechanism relates to how active participation and two-way communication runs on the organization. To fill the process step in the Van Grembergen framework, recommendations were made from the mapping results and questionnaires from the ITIL framework. This process step is directly related to IT governance related to decision making and monitoring during the system transition process.

Recommendations for improvements that are of a nonmandatory type:

a. Designing an evaluation mechanism regularly

b. Add a multilevel validation

c. Designing an excalation process approval handling mechanism d. Designing a matrix of categories based on priority.

e. Increase PIR by including the information needed.

f. Designing a mechanism for handling violations of IT Change Management (unauthorized changes) processes.

g. Creating a mechanism for making failure reports.

h. Add information components about business objectives.

i. Planning an emergency handling mechanism due to urgent business

\section{ACKNOWLEDGMENT}

Author might want to express gratitude toward Institut Teknologi Sepuluh Nopember and the Ministry of Research, Technology and Higher Education of Indonesia for supporting the research.

\section{REFERENCE}

[1] P. Weill and J. W. Ross, IT Governance: How Top Performers Manage IT Decision Rights for Superior Results. Boston, MA: Harvard Business School Press, 2004.

[2] J. W. Lainhart IV, "Why IT Governance Is a Top Management Issue," J. Corp. Account. Financ., vol. 11, no. 5, pp. 33-40, 2000.

[3] S. De Haes and W. Van Grembergen, "IT governance structures, processes and relational mechanisms: Achieving IT/business alignment in a major Belgian financial group," in Proceedings of the Annual Hawaii International Conference on System Sciences, 2005, p. 237.

[4] M. Iskandar and N. A. M. Salleh, "IT governance in ecommerce environment: Cases from airline industry," in 2010 International Conference for Internet Technology and Secured Transactions, 2010. 